\title{
Bending for love: losses and gains of sexual dimorphisms are strictly correlated with changes in the mounting position of sepsid flies (Sepsidae: Diptera)
}

\author{
Nalini Puniamoorthy, Kathy Feng-Yi Su and Rudolf Meier*
}

\author{
Address: Department of Biological Sciences, National University of Singapore, 14 Science Dr 4, Singapore 117543, Singapore \\ Email: Nalini Puniamoorthy - sepsids@gmail.com; Kathy Feng-Yi Su - kathysufy@gmail.com; Rudolf Meier* - dbsmr@nus.edu.sg \\ * Corresponding author
}

Published: 21 May 2008

BMC Evolutionary Biology 2008, 8:155 doi:10.1 186/147|-2|48-8-155

This article is available from: http://www.biomedcentral.com/l47|-2/48/8/155

(c) 2008 Puniamoorthy et al; licensee BioMed Central Ltd.

This is an Open Access article distributed under the terms of the Creative Commons Attribution License (http://creativecommons.org/licenses/by/2.0), which permits unrestricted use, distribution, and reproduction in any medium, provided the original work is properly cited.

\begin{abstract}
Background: Sexually dimorphic structures contribute the largest number of morphological differences between closely related insect species thus implying that these structures evolve fast and are involved in speciation. The current literature focuses on the selective forces that drive these changes, be it 'sexual conflict' or 'female choice'. However, there are only few studies examining the function of sexual dimorphisms and even fewer that investigate how functional changes influence dimorphisms. This is largely due to the paucity of taxa for which the morphology, behavior, and phylogenetic relationships for multiple species are known. Here we present such data for sepsid flies. Sepsids have starkly dimorphic forelegs whose function can be documented under laboratory conditions. We use data from 10 genes to reconstruct the phylogenetic relationships for 33 species and test whether mounting positions are correlated with the presence and absence of sexual dimorphisms in the forelegs.

Results: The phylogenetic tree fully resolves the relationship with 29 of the 31 nodes of the tree having a posterior probability of I.0. Twenty-eight of the $3 \mathrm{I}$ sepsid species have sexually dimorphic forelegs. All 28 species with such forelegs have the same mounting technique whereby the male uses his modified forelegs to grasp the female wingbase. Mapping mounting behavior and foreleg morphology onto the tree reveals that the wing grasp evolved once and was reduced twice. All changes in the mounting behavior are strictly and statistically significantly correlated with the origin and losses of sexually dimorphic legs (concentrated changes test: $P<0.00 I$ ); i.e., the two species that have independently lost the wing grasp have both also re-evolved monomorphic legs. The wing grasp in these species is replaced with a novel but very similar mounting technique not involving the forelegs: the males bend their abdomens forward and directly establish genital contact to the female. In addition, one of the secondarily monomorphic species, Sepsis secunda, has evolved a new sexual dimorphism, a 'bump' on the dorsal side of the 4th tergite, which is now touching the ventral side of the female abdomen.
\end{abstract}

Conclusion: Our study reveals that the evolution of sexually dimorphic legs in Sepsidae can only be understood once the function of the legs during mating is considered and the relationships of species with and without sexual dimorphisms are known. We demonstrate that homoplasy in sexually dimorphic structures can be due to homoplasy in mating behavior. We furthermore document that the two species with secondarily monomorphic legs have independently replaced the typical sepsid wing grasp with very similar, new mounting techniques. This suggests that convergent evolution may be common in mating behaviors. 


\section{Background}

Most closely related species of insects differ exclusively or predominantly with regard to sexually dimorphic traits $[1,2]$. This observation implies that these traits evolve fast and are likely to be involved in speciation. Understanding the evolution of sexual dimorphisms is thus crucial for understanding the impressive species diversity of the Insecta, the most speciose clade of multicellular animals [3]. This has made the study of sexual dimorphisms also one of the most important goals of modern evolutionary biology.

Much of the literature focuses on the theoretical issues that drive the sexual selection that is responsible for the origin and maintenance of sexual dimorphisms. Traditionally, the fast evolution of male ornaments had been attributed to selection via female choice [4]. Some empirical data and genetic models had shown that this choice could be driven by direct benefits that increase survivorship $[5,6]$ or indirect genetic benefits that could improve viability and/or the attractiveness of the offspring [7-12]. However, there is an alternative explanation for the fast evolution of sexual dimorphisms. The unequal investments in gametes by males and females leads to a conflict of interest between the sexes ("sexual conflict" $[13,14]$ ). Males have a higher interest in multiple matings than females and may thus try to coerce females into being polygamous. As a result both sexes can become involved in a sexually antagonistic arms race and evolve mechanisms to gain control over reproduction, regardless of the costs to the other sex $[15,16]$. Evidence for such morphological coevolution between male and female reproductive characters has been found across a number of insect groups like Coleoptera (e.g.: Bruchidae and Dytiscidae), Hemiptera (e.g.: Gerridae) and Diptera (e.g.: Empididae and Scathophagidae) [17-25].

However, comparatively little is known about the function of many sexually dimorphic structures and even less is known about how the function of these structures changes over evolutionary time. One reason for this gap in our knowledge is that studying the evolution of function requires concurrent information on the morphology, behavior and phylogeny of multiple species. Only then can functional changes be mapped onto a phylogenetic hypothesis. Unfortunately, for many sexually dimorphic features, only the morphology has been documented in detail and it is often unclear how they are being used. This is particularly so for male genitalia whose function is difficult to study because they interact with internal elements of the female reproductive tract $[26,27]$. Even if the function for a particular structure has been studied in great detail, information is usually only available for one or a few species [28] and if there is information for several species, the phylogenetic relationships are frequently unknown. As a consequence there are only few studies that have documented the evolution of the function of sexually dimorphic structures $[18,29-33]$. Here, we use a wealth of information on the morphology and function of the male forelegs for 31 species of Sepsidae (Diptera: Cyclorrhapha) to document how sexual dimorphisms are correlated with mating behavior over evolutionary time.

Over the past 30 years, sepsid flies have become model organisms in the study of behavior in general and sexual selection in particular [34-43]. Sepsids are ideal models because some of the structures involved in the interactions between males and females are easily accessible and display stark sexual dimorphism [44,45]. Furthermore, sepsids can be maintained in the laboratory and some aspects of their mounting and copulation behavior can be video-taped and studied without dissection. The most interesting sexually dimorphic structure that is easily accessible is the forelegs. In most sepsid species, the males use their forelegs for grasping the female wing base prior to copulation. The forelegs are often strongly sexually dimorphic, with female legs being unmodified while the male legs display a wide variety and species-specific cuticular outgrowths, indentations, and/or modified bristles (see Figures 1 and 2). The males of most sepsid species will indiscriminately jump on females and attempt to clamp to the female's wing base. It is here that the morphological modifications of the male forelegs play a major role. They tightly mesh with the wing veins and cells of the female wing [44,45] and help the male during the next stage of mating, a rodeo-like struggle that is found in most species and that starts after the male has mounted the female [34,46-48]. The females of many sepsid species use vigorous shaking in order to dislodge and/ or test the stamina of the male $[40,43,49,50]$. In addition, females usually bend their abdomen ventrally so that the males cannot establish genitalic contact without female consent $[34,42]$. Copulation can only be initiated once the female lifts the tip of her abdomen, which may or may not occur in response to male behaviors [38,51,52]. Many copulation attempts by males are ultimately aborted either because the males voluntarily dismount or because males are dislodged through shaking [38].

Sexually dimorphic forelegs are found in the vast majority of sepsid species. However, monomorphic legs are known for six species: Orygma luctuosum Meigen 1830, three species of Perochaeta Duda 1926, Sepsis duplicata Haliday 1838, and S. secunda (Melander et Spuler 1917). Here, we document the foreleg morphology and mounting behavior for two outgroup species, 3 species of Sepsidae with monomorphic legs and 28 species of Sepsidae with sexually dimorphic legs. We reconstruct the phylogenetic relationships among all species based on sequence data for 10 genes, map foreleg morphology and mounting behavior 

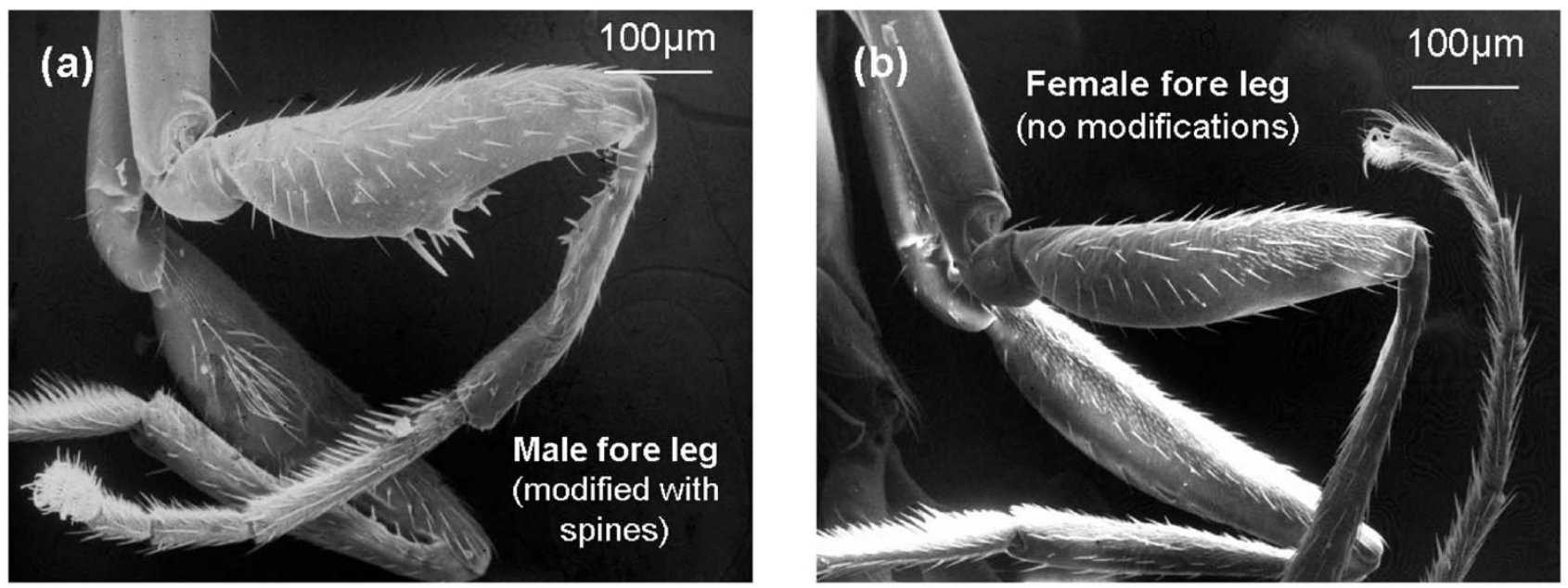

Figure I

Forelegs of Sepsis dissimilis Brunetti, I910. (a) Male foreleg; (b) Female foreleg.

onto the phylogenetic tree, and use a concentrated change test [53] to establish whether the gains and losses of dimorphic forelegs are correlated with changes in how the forelegs are used during mounting.

\section{Methods \\ Morphology}

The forelegs of ethanol-preserved males and females for the 33 species were removed from the thorax and both the anterior and posterior views of the femur, tibia and trochanter were documented at $200 \times$ and $400 \times$ magnification using a Hirox microscope and the software DigiScale. Drawings of the anterior view of the male femur and trochanter were prepared based on these digital images and comparisons with additional specimens of the same species. The morphology of the male foreleg was then compared to the morphology of the female foreleg. Legs were regarded as sexually monomorphic when male and female forelegs could not be differentiated from each other upon removal from the thorax. For certain select species, a Jeol JSM-7220A Scanning Electron Microscope was used to document additional dimorphic structures.

\section{Rearing and Mating experiments}

Laboratory cultures were established for 30 sepsid species based on females collected in the field. The parental cultures were maintained under controlled conditions in incubators and supplied regularly with dung and sugar water. Mating experiments involved virgin flies that were obtained by sexing newly emerged flies within 24 hours of eclosion, keeping males and females as virgins in separate containers. Mating trials were carried out approximately four days after separation. A male and a female were introduced into a small Petri dish and their interaction was recorded using a Leica MZ16A Microscope camera and a VCR. The recording started upon the introduction of both flies into the Petri dish and ended after a successful copulation or after 25 minutes if the males did not attempt to mount. The analog recordings were digitized using the non-linear editing software, Final Cut Pro, and studied frame by frame ( 1 frame $=1 / 25$ seconds) in order to document the mounting behavior of the different species in detail. The number of recordings per species is listed in the results section. Information on the mating behavior of Saltella sphondylii was obtained from an earlier study by Martin and Hosken [54].

\section{Phylogenetic Relationships}

We reconstructed the relationships among the 33 species based on 10 genes (18S, 28S, AATS, EF1a, Histone 3, 12S, 16S, COI, COII, CYB; for details see [55]; for Genbank accession numbers [see Additional file 1]). The data set was subjected to a Bayesian analysis as implemented in MrBayes 3.1 [56]. We used MrModeltest [57] to establish that the GTR + I + G model was favored for all genes by both the Akaike information criterion and hierarchical likelihood ratio testing. The data set was analyzed for $3,000,000$ generations and a tree was sampled every 300 generations $(=10,000$ trees $)$ with a subsequent burn-in of 2500 trees.

\section{Character mapping and concentrated change test}

Sexual dimorphism (SD) was scored as a presence/ absence character (sexually dimorphic legs absent $=0$; present $=1)$. With regard to the mounting behavior $(\mathrm{MB})$, we used the role of the forelegs to define two character states. State 0 was used to code those species where the male foreleg is not used to grasp the female wing base. 


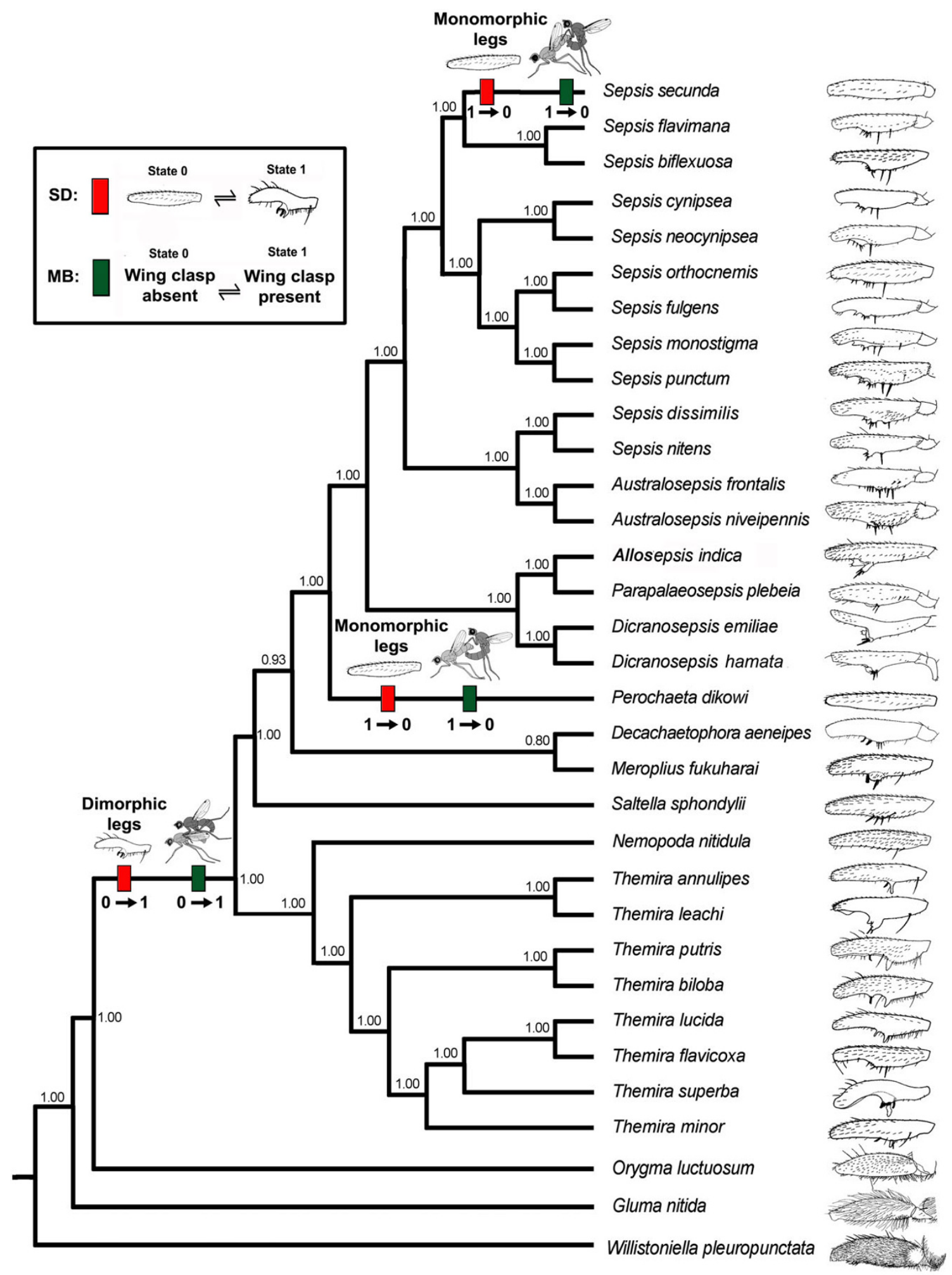

\section{Figure 2}

Evolution of sexual dimorphism (SD) and mounting behavior (MB) in Sepsidae. Red hatchmarks represent sexually dimorphic forelegs and green hatchmarks represent the mounting behavior. Numbers below hatchmarks indicate character state number. Posterior probability values are indicated at the branch nodes. 
Presence of the grasp was coded as character state 1 . To test whether changes in behavior and morphology are correlated, we mapped both binary characters onto the phylogenetic tree and used the concentrated change test [53] as implemented in MacClade 4 [58] using the Sepsidae node as the target clade.

\section{Results Morphology}

Out of the 31 sepsid species included in this study, the following 28 have sexually dimorphic forelegs. The number of mating trials with successful mountings is listed after the species names: Australosepsis frontalis (Walker, 1860), $\mathrm{n}=15$; A. niveipennis (Becker, 1903), $\mathrm{n}=17$; Decachaetophora aeneipes (de Meijere, 1913), $\mathrm{n}=10$; Dicranosepsis emiliae (Ozerov, 1992), $\mathrm{n}=13$; D. hamata (de Meijere, 1911), n = 9; Meroplius fukuharai (Iwasa, 1984), n = 5; Nemopoda nitidula (Fallen, 1820), $\mathrm{n}=8$; Parapaleosepsis plebeia Duda, 1926, $\mathrm{n}=15$; Saltella sphondylii (Schrank, 1803), Sepsis biflexuosa Strobl, 1893, $\mathrm{n}=3$; S. cynipsea (Linnaeus, 1758), $\mathrm{n}=20 ; \mathrm{S}$. dissimilis Brunetti, 1910, $\mathrm{n}=20 ; \mathrm{S}$. flavimana Meigen, 1826, $\mathrm{n}=5 ; \mathrm{S}$. fulgens Meigen, 1826, $\mathrm{n}$ $=10 ; S$. (Allosepsis) indica Wiedemann, 1824, $\mathrm{n}=20 ; S$. monostigma Thomson, 1869, $\mathrm{n}=5 ;$ S. neocynipsea Melander et Spuler, 1917, $\mathrm{n}=5 ; S$. nitens Wiedemann, $1824, \mathrm{n}=7 ;$ S. orthocnemis Frey, 1908, $\mathrm{n}=6 ;$ S. punctum (Fabricius, 1794), $\mathrm{n}=10$; Themira annulipes (Meigen, 1826), $\mathrm{n}=4 ;$ T. biloba Andersson, 1975, $\mathrm{n}=3$; T. flavicoxa Melander et Spuler, 1917, $\mathrm{n}=10 ; T$. leachi (Meigen, 1826), $\mathrm{n}=3 ; T$. lucida (Staeger, 1844), $\mathrm{n}=15 ; T$. minor (Haliday, 1833), $\mathrm{n}=15 ; \mathrm{T}$. putris (Linnaeus, 1758) $\mathrm{n}=15$; and $T$. superba (Haliday, 1833) $\mathrm{n}=20$. The forelegs of $N$. nitidula may at first sight appear almost monomorphic, but this is due to the fact that the dimorphic elements are very small. They are thus here documented in a separate micrograph [see Additional file 2]. The three species with sexually monomorphic forelegs in our study were Orygma luctuosum, $\mathrm{n}=14$, Perochaeta dikowi Ang et al., 2008, $\mathrm{n}=20$ and Sepsis secunda, $\mathrm{n}=8$. The two outgroups, Gluma nitida McAlpine, 1991 and Willistoniella pleuropunctata (Wiedemann, 1824) also have monomorphic forelegs (see Figure 2).

\section{Mounting behavior}

The mounting behavior was documented for all of the above mentioned sepsid species except Saltella sphondylii for which the behavior has been described in the literature [54]. All 28 species with sexually dimorphic legs exhibit the "typical" sepsid mount where the male jumps/climbs onto the female and uses his modified forelegs to clasp onto the base of her wing (see Figure 3a). Video clips documenting the mounting behavior are provided as additional files [see Additional files 3, 4 and 5] (or visit the following websites [59-61]). However, the three species that have monomorphic forelegs have mounting tech- niques not involving the male foreleg. The males of Orygma luctuosum jump on the female and wrap their fore and mid legs around the female thorax [see Additional file 6] (or visit the following website [62]). This is followed by a brief struggle whereby the female either attempts to shake off the male, often using her legs to 'kick' him, or by rolling over in order to dislodge the male. In successful mating trials, upon establishing genital contact, the male rests his forelegs on the female's postpronotal callus and not around the wing base.

The mounting behaviors of the two other species with monomorphic legs, Sepsis secunda and Perochaeta dikowi, are very similar to each other but differ considerably from the behavior of O. luctuosum. In P. dikowi (see Figure $3 \mathrm{~b}$ ) and S. secunda (see Figure 3c) males approach the females from behind and bend their abdomen ventroanteriad in order to directly establish genital contact without the use of the male forelegs. Once genital contact has been established, copulation starts. The only difference between the two species is that in P. dikowi, the males initially extend their surstylus beyond the female genitalia and touch the ventral side of the female abdomen near sternite three. The surstylus then slides posterior before establishing genital contact [see Additional file 7] (or visit the following website [63]). During copulation the male forelegs rest on the females' postpronotal callus (for a detailed description of mating behavior see [64]). In S. secunda the males will first establish genital contact and then place their forelegs loosely and mid-way along the anterior edge of the female wing [see Additional file 8] (or visit the following website [65]).

\section{Phylogeny and character evolution}

The dataset was subjected to a Bayesian analysis and three independent analyses resulted in similar tree topologies, comparable clade probabilities and substitution model parameters. This suggested that consistent estimates of the posterior probability (PP) distributions had been obtained. Our analysis yielded a very well resolved tree placing Orygma luctuosum as sister group to all the remaining sepsids. All but two nodes had PP values of 1.00 (see Figure 2). The dimorphism and behavior characters were mapped onto the phylogenetic hypothesis. The presence of a sexually dimorphic foreleg is strictly correlated with a mating position involving the wing grasp (concentrated changes test using all of Sepsidae as target clade: two losses in SD with two losses in $\mathrm{MB}, P=0.000742)$. All three changes in the sexual dimorphism character occur on the same branches as the changes in mounting behavior (see Figure 2).

\section{Discussion}

Mounting behavior in Sepsidae is strictly and statistically significantly correlated with the origin and losses of sexual 
(a)
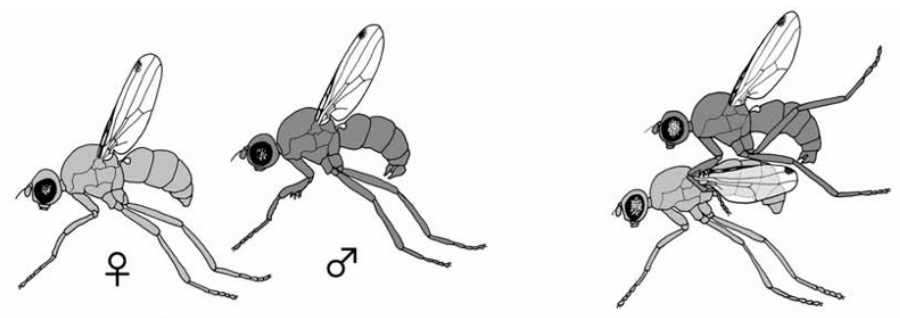

(b)
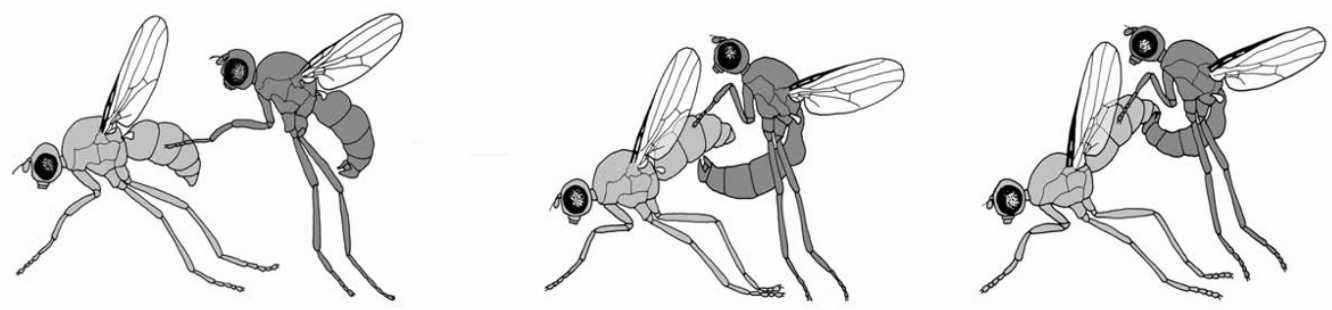

(c)
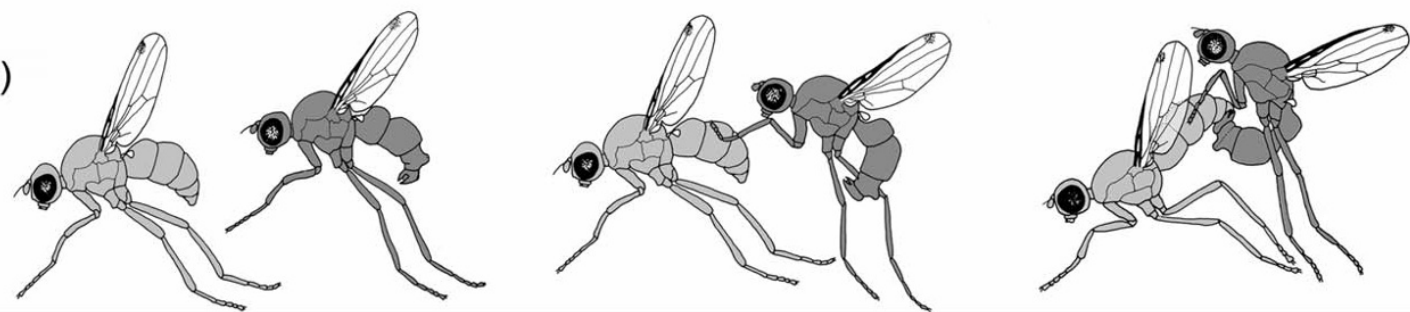

\section{Figure 3}

Mounting techniques in Sepsidae. (a) "Typical" sepsid mount: male uses modified forelegs to clasp female wingbase; (b) Novel mounting technique in Perochaeta dikowi: male bends abdomen ventro-anteriad and makes contact with the ventral side of the female abdomen with his surstylus before sliding posterior to establish genital contact; (c) Novel mounting technique in Sepsis secunda: male bends abdomen ventro-anteriad to establish direct genital contact.

dimorphisms. The "typical" mounting position of Sepsidae involving the wing grasp only evolved once and within the family (see Figure 2; red hatchmark) and the origin of this mounting position coincides with the origin of sexually dimorphic forelegs (see Figure 2; green hatchmark). The males of the three sepsid species with monomorphic forelegs, Orygma luctuosum, Perochaeta dikowi, and Sepsis secunda place the forelegs on different parts of the female body. Given its placement on the tree, the mounting behavior and lack of sexual dimorphism is plesiomorphic in O. luctuosum. In fact, not only do the forelegs of $O$. luctuosum closely resemble the legs of the outgroups (see Figure 2) but the mounting behavior is also very similar to the behaviors of the outgroups Gluma nitida [66] and Willistoniella pleuropunctata (see Figure 4). For instance, male coelopids have been observed to mount females and wrap their legs around the female thorax and as observed in O. luctuosum, the females will 'kick' the males with their midlegs and even roll over $[67,68]$. Other acalyptrate flies like Protopiophila litigata (Diptera: Piophilidae) and Dryomyza anilis (Diptera: Dryomyzidae) also exhibit similar mounting behaviors. For example, upon mounting, $P$. litigata males rest their fore tarsi on the female postpronotum [69] while in D. anilis, the male forelegs are placed on the female head [70].

However, the monomorphic legs of Perochaeta dikowi and Sepsis secunda are due to the convergent loss of the male leg armature in two distantly related clades of Sepsidae. A study of the mating behavior reveals that in both species, the forelegs are no longer used for grasping the female wingbase. One can imagine many different ways of replacing the typical sepsid mounting position with a new mounting technique. Yet, $P$. dikowi and $S$. secunda have convergently invented near identical, new behaviors. In both species, the male approaches the female from behind. In both species, the males curl their abdomens forward in order to touch the female abdomen with their claspers. In both species, it is only afterwards that the male legs play a minor role in mating: in $P$. dikowi, males rest their fore tarsi on the female postpronotal callus whilst the males of $S$. secunda rest their fore tarsi mid-way along the female wing margin. Convergence in morphology is often driven by similarities in habitat and environment. However, there are no aspects of the known autecology of these two species that could explain the convergent evolution of the mounting behavior. Both are typical scavenger 


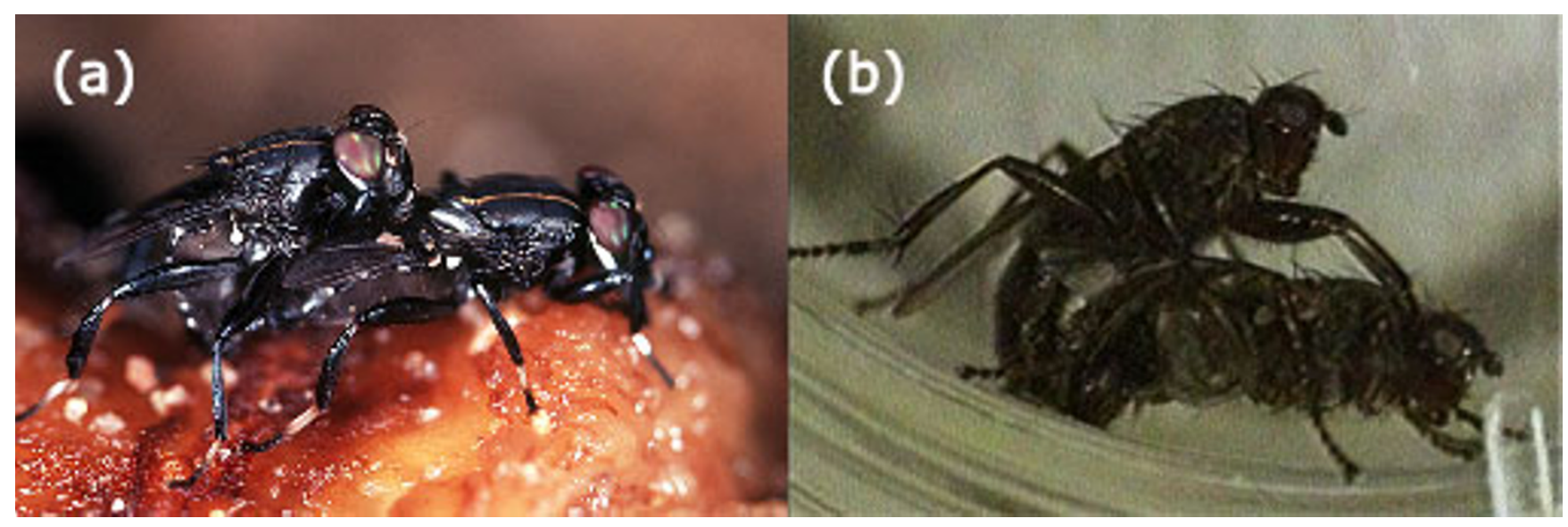

Figure 4

Flies in copula. Male forelegs not clasping female wingbase. (a) Willistoniella pleuropunctata; (b) Orygma luctuosum.

flies that use cow dung as breeding substrate. Sepsis secunda is mostly found on open pastures in hot and dry areas of North America, while P. dikowi is only known from forests at mid-elevation sites in the tropics [64]. Furthermore, both species co-occur in the same habitat with other sepsid species that have the "normal" wing grasp.

Evolutionary biologists have long predicted and documented convergence in sexually dimorphic structures [45]. Some authors attribute the convergent evolution of correlated traits to highly conserved patterns of pleiotropy as a potential mechanism for channeling sexual shape dimorphism in Diptera [71]. These hypotheses address the proximate causes for the convergent evolution of sexual dimorphisms and should be complemented with studies that can address the ultimate causation. We suggest that the ultimate reasons for why similar genetic architecture may be utilized to produce convergent dimorphisms are convergent changes in mating behavior. In our case the convergent loss of the wing clamp leads to the convergent loss of the leg dimorphisms. Yet, more intriguing is our finding of convergent evolution of a very specific new mounting behavior which may suggest that highly conserved patterns of pleiotropy and a conserved genetic architecture may also exist for behavior.

We had previously outlined that there is only scant information on how the function of sexually dimorphic traits change over time. Our study helps to fill the void. In the sepsid outgroups and Orygma luctuosum the fore femora and tibiae of the males function like the same structure in most flies. However, in most species of Sepsidae the male forelegs acquire an additional function, i.e., the clamping of the females' wingbase and as a result a new sexual dimorphism evolves. Subsequently, the male forelegs undergo extensive and fast modification as revealed in
Figure 1 where all 28 species with sexually dimorphic legs have species-specific modifications. However, as P. dikowi and S. secunda document sexual dimorphisms can also disappear once a structure loses its role in mating behavior.

There are still relatively few studies that document how a behavioral change is correlated with a morphological change $[18,29,31,32]$. However, a similar case is also known from seaweed flies (Diptera: Coelopidae) where the male foretarsus touches the female antenna during mating [72]. A new morphological structure, a thumbnaillike process, evolved on the basitarsus of males and it must be evolving rapidly because it differs between the different species of Coelopidae [73]. The antlered flies in the genus Phytalmia (Diptera: Tephritidae) provide another example. Males have cuticular projections on the head (antlers) that are used in male-male combat for territory and the complexity of the antler shapes differs quite drastically between species [74]. Species with complex antlers have simple behavioral repertoires whilst those with simpler antlers evolved more complex behaviors involving the fore, mid and hind legs (e.g.: 'wing-locking' and 'stilting' [33]).

The novel mounting technique in Perochaeta dikowi and Sepsis secunda is not only associated with the loss of sexually dimorphic legs, but also associated with the gain of new sexual dimorphisms. In $P$. dikowi the males have modified fourth or fifth sternites that form brushes. These are used during copulation [64]. In S. secunda, the males have sexually dimorphic $4^{\text {th }}$ tergites. Normally, this tergite is monomorphic which is not surprising given that the dorsal side of the male abdomen is not involved in the mating behavior of most sepsids. However, in S. secunda the male tergites touch the female when the male abdo- 
men is curled forward [see Additional file 8] (or visit the following website [65]). A new dorsal, bump-like extension of the tergite four evolves and this tergite becomes strongly sexually dimorphic (see Figure 5; SEM picture). In addition, $S$. secunda has an elongated abdomen (elongated segments I \& II). In particular, the posterior part of the segment II is strongly lengthened and connected to a distinctly constricted tergite three (see Figure 5; red arrow). This constriction is likely related to the new mating behavior that requires the male to bend his abdomen forward. Indeed, this constriction closely resembles the wasp waist of parasitoid wasps that need to have similar flexibility in order to use their ovipositor for injecting poison and/or eggs into a host. It appears likely that these morphological changes in $S$. secunda occurred rapidly because they are not found in its sister group, $S$. duplicata, and the two species are very similar with regard to the barcoding gene COI (1.97\%; normal distances in most closely related Diptera species $>3 \%[75]$ ).

Throughout the discussion, we often implicitly assumed that the change in behavior preceded the loss of the sexual dimorphism although technically the strict correlation between the two traits could also imply the reverse order. However, based on functional considerations it appears unlikely that the reduction of the male leg armature preceded the behavioral change given that the leg armature has been experimentally shown to be important for successful mating in sepsids $[37,44,51,76]$. Reversing the order of events would also not alter our finding of a strict correlation between mounting behavior and the losses and gains of sexual dimorphisms in Sepsidae.

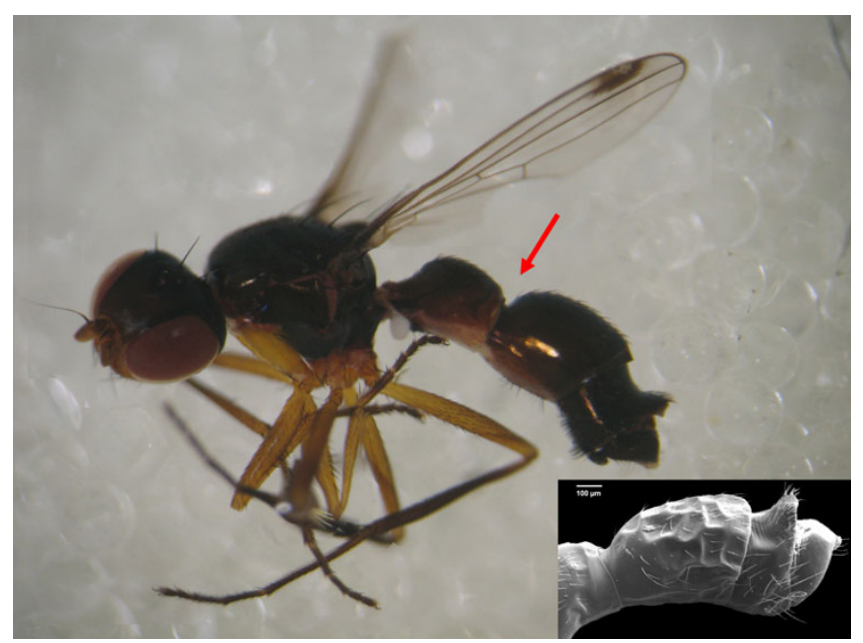

\section{Figure 5}

Sepsis secunda. Habitus picture of male; SEM of sexually dimorphic dorsal 'bump'.
Several groups of Diptera are important models for investigating sexual conflict. A number of studies have documented coevolution between male and female reproductive characters. For instance, Minder et al. (2005) show that the sperm length in males evolves with the length of spermathecal ducts in females across several species of yellow dung flies (Scathophagidae) [22]. In Drosophila melanogaster (Drosophilidae) female resistance evolves in response to the harm caused by male accessory gland proteins that reduce female fitness and are transferred during copulation [77-80]. Furthermore, Bonduriansky and Rowe (2005) argued that intralocus sexual conflict reduces the heritability of sexual traits in Prochyliza xanthostorna (Piophilidae) and Otronen (1994) suggested that inter-sexual conflict over mating patterns led to repeated copulations in Dryomyza anilis (Dryomyzidae) [81]. In Sepsidae, some authors argued for sexual conflict $[38,47,82]$ while others claimed that the evolution of sexual dimorphisms is driven by female choice [35,37].

In our study, we have identified several elements that are characteristic of an arms race: morphological variation among close relatives as well as a correlation between morphology and behavior. However, we only documented this coevolution within the male sex and in order to document sexual conflict, we would also need to document coevolutionary responses in the females (see [45]). In the absence of this evidence, we cannot attribute the diversity of male foreleg armature to sexually antagonistic coevolution.

\section{Conclusion}

One of the most powerful indirect techniques in evolutionary biology is using the comparative method to investigate convergent evolution [83]. By combining behavioral, morphological, and phylogenetic data, we are here able to show that sexual dimorphisms evolve fast and convergently in Sepsidae. Homoplasy is not restricted to sexual dimorphisms, but also affects mounting behavior. Our study furthermore documents how important it is to study the function of sexually dimorphic structures.

\section{Authors' contributions}

NP conducted all the mating behavior experiments in this paper. Both NP and KF-YS were responsible for the morphological documentation of the various sexually dimorphic and monomorphic structures. The molecular work i.e. DNA matrix assembly was primarily carried out by KFYS with help from Ms. Sujatha N. Kutty. RM contributed to the conception of this research and performed all the phylogenetic analyses in the paper. All authors read and approved the final manuscript. 


\section{Additional material}

\section{Additional file 1}

Table 1. List of species and Genbank accession numbers for 10 genes. Click here for file

[http://www.biomedcentral.com/content/supplementary/14712148-8-155-S1.xls]

\section{Additional file 2}

Figure 6 (Male foreleg of Nemopoda nitidula). Weakly modified male foreleg with an anterior bristle and short row of posterior spines as indicated by red arrows.

Click here for file

[http://www.biomedcentral.com/content/supplementary/1471-

2148-8-155-S2.png]

\section{Additional file 3}

Video A1 (Themira + Nemopoda). Compiled video of mounting clips and foreleg drawings for eight Themira species and Nemopoda nitidula, all with sexually dimorphic forelegs.

Click here for file

[http://www.biomedcentral.com/content/supplementary/14712148-8-155-S3.mp4]

\section{Additional file 4}

Video A2 (Australosepsis + Sepsis). Compiled video of mounting clips and foreleg drawings for two Australosepsis species and 10 Sepsis spp., all with sexually dimorphic forelegs.

Click here for file

[http://www.biomedcentral.com/content/supplementary/14712148-8-155-S4.mp4]

\section{Additional file 5}

Video A3 (Five genera of sepsid species). Compiled video of mounting clips and foreleg drawings for Decachaetaphora aeneipes, Meroplius fukuharai, Allosepsis indica, Parapaleosepsis plebeia, and two Dicranosepsis species, all with sexually dimorphic forelegs.

Click here for file

[http://www.biomedcentral.com/content/supplementary/14712148-8-155-S5.mp4]

\section{Additional file 6}

Video B1 (Orygma luctuosum). Video of mounting clips and foreleg drawing for Orygma luctuosum with sexually monomorphic forelegs. Click here for file

[http://www.biomedcentral.com/content/supplementary/14712148-8-155-S6.mp4]

\section{Additional file 7}

Video B2 (Perochaeta dikowi). Video of mounting clips and foreleg drawing for Perochaeta dikowi with sexually monomorphic forelegs.

Click here for file

[http://www.biomedcentral.com/content/supplementary/1471-

2148-8-155-S7.mp4]

\section{Additional file 8}

Video B3 (Sepsis secunda). Video of mounting clips and foreleg drawing for Sepsis secunda with sexually monomorphic forelegs.

Click here for file

[http://www.biomedcentral.com/content/supplementary/14712148-8-155-S8.mp4]

\section{Acknowledgements}

The authors thank numerous colleagues who made intellectual and material contributions for this study. In particular, we would like to mention Torsten Dikow, Michael von Tschirnhaus, Thomas Pape, Guanyang Zhang, Michael Balke, and Wei Song Hwang. This study was financially supported by grant R-154-000-256-I 12 from the Ministry of Education in Singapore and the US National Science Foundation Grant No. 0334948.

\section{References}

I. Arnqvist G: Comparative evidence for the evolution of genitalia by sexual selection. Nature (London) 1998, 393(6687):784-785.

2. Eberhard WG: Sexual Selection and Animal Genitalia. Eberhard, W G Sexual Selection and Animal Genitalia Xii+244p Harvard University Press: Cambridge, Mass, USA; London, England Illus 1985:XII+244P.

3. Groombridge B: Global biodiversity: Status of the Earth's living resources. London, Chapman and Hall; 1992.

4. Darwin C: The Descent of Man, and Selection in Relation to Sex. London, John Murray; I87I.

5. Gwynne DT: Courtship feeding in katydids (Orthoptera: Tettigoniidae). Investment in offspring or in obtaining fertilizations? American Naturalist 1986, I 28:342-352.

6. Møller AP, Jennions MD: How important are direct fitness benefits of sexual selection? Naturwissenschaften 200I, 88:40I-4I5.

7. Andersson M: Female choice selects for extreme tail length in a widowbird. Nature 1982, 299:8|8-820.

8. Iwasa Y, Pomiankowski A: Good parent and good genes models of handicap evolution. Journal of Theoretical Biology 1999, 200(I):97-109.

9. Neff BD, Pitcher TE: Genetic quality and sexual selection: an integrated framework for good genes and compatible genes. Molecular Ecology 2005, 14:19-38.

10. Petrie M: Improved growth and survival of offspring of peacocks with more elaborate trains. Nature 1994, 371:598-599.

II. Pomiankowski A, Iwasa Y: How does mate choice contribute to exaggeration and diversity in sexual characters? Economics in nature: social dilemmas, mate choice and biological markets 200I:203-220.

12. Sheridan L, Pomiankowski A: Female choice for spot asymmetry in the Trinidadian guppy. Animal Behaviour 1997, 54(6): $1523-1530$.

13. Chapman T, Arnqvist G, Bangham J, Rowe L: Sexual conflict. Trends in Ecology \& Evolution 2003, I8(I):41-47.

14. Parker GA: Sexual selection and sexual conflict. In Sexual Selection and Reproductive Competition in Insects Edited by: Blum MS, Blum NA. New Jersey, Academic; 1979:123-166.

15. Gavrilets S, Arnqvist G, Friberg U: The evolution of female mate choice by sexual conflict. Proceedings Royal Society of London Series B Biological Sciences 200I, 268( I 466):53I-539.

16. Holland B, Rice WR: Perspective: Chase-away sexual selection: Antagonistic seduction versus resistance. Evolution 1998, 52:1-7.

17. Arnqvist G, Rowe L: Antagonistic coevolution between the sexes in a group of insects. Nature 2002, 41 5(6873):787-789.

18. Bergsten J, Miller KB: Phylogeny of diving beetles reveals a coevolutionary arms race between the sexes. PLOS ONE 2007, 2(6): Unpaginated.

19. Funk DH, Tallamy DW: Courtship role reversal and deceptive signals in the long-tailed dance fly, Rhamphomyia longicauda. Animal Behaviour 2000, 59:4II-42I.

20. Hosken DJ, Garner TWJ, Ward PI: Sexual conflict selects for male and female reproductive characters. Current Biology 200I, I I(7):489-493.

21. Miller KB: The phylogeny of diving beetles (Coleoptera: Dytiscidae) and the evolution of sexual conflict. Biological Journal of the Linnean Society 2003, 79:359-388.

22. Minder AM, Hosken DJ, Ward PI: Co-evolution of male and female reproductive characters across the Scathophagidae (Diptera). Journal of Evolutionary Biology 2005, I 8(I):60-69.

23. Morrow EH, Arnqvist G: Costly traumatic insemination and a female counter-adaptation in bed bugs. Proceedings of the Royal Society of London Series B-Biological Sciences 2003, 270(153I):2377-238I. 
24. Roenn J, Katvala M, Arnqvist G: Coevolution between harmful male genitalia and female resistance in seed beetles. Proceedings of the National Academy of Sciences of the United States of America 2007, I 04(26): | 092| - 10925.

25. Rowe L, Westlake KP, Currie DC: Functional significance of elaborate secondary sexual traits and their evolution in the water strider genus Rheumatobates. Canadian Entomologist 2006, I 38(4):568-577.

26. Eberhard WG: Male-female conflict and genitalia: failure to confirm predictions in insects and spiders. Biol Rev Camb Philos Soc 2004, 79(I): 121-186.

27. Hosken DJ, Stockley P: Sexual selection and genital evolution. Trends Ecol Evol 2004, 19(2):87-93.

28. Eberhard WG, Pereira F: Functional morphology of male genitalic surstyli in the dungflies Achisepsis diversiformis and $\mathbf{A}$ ecalcarata (Diptera: Sepsidae). Journal of the Kansas Entomological Society 1996, 69(4):43-60.

29. Arnqvist G, Rowe L: Correlated evolution of male and female morphologies in water striders. Evolution Int J Org Evolution 2002, 56(5):936-947.

30. Eberhard W: Multiple origins of a major novelty: moveable abdominal lobes in male sepsid flies (Dipera: Sepsidae), and the question of developmental constraints. Evolution and Development 200I, 3(3):206-222.

31. Emlen DJ: Phylogenetic evidence for an association between tunneling behavior and the evolution of horns in dung beetles (Coleoptera : Scarabaeidae : Scarabaeinae). Coleopterists Bulletin 2006, 60(5):47-56.

32. Koene JM, Schulenburg $H$ : Shooting darts: co-evolution and counter-adaptation in hermaphroditic snails. BMC Evolutionary Biology 2005, 5:

33. Schutze MK, Yeates DK, Graham GC, Dodson G: Phylogenetic relationships of antlered flies, Phytalmia Gerstaecker (Diptera: Tephritidae): the evolution of antler shape and mating behaviour. Australian Journal of Entomology 2007, 46:28I-293.

34. Allen GR, Simmons LW: Coercive mating, fluctuating asymmetry and male mating success in the dung fly Sepsis cynipsea. Animal Behaviour 1996, 52:737-74l.

35. Baena ML, Eberhard WG: Appearances deceive: female 'resistance' behaviour in a sepsid fly is not a test of male ability to hold on. Ethology Ecology \& Evolution 2007, I 9(I):27-50.

36. Eberhard WG, Huber BA: Copulation and sperm transfer in Archisepsis flies (Diptera, Sepsidae) and the evolution of their intromittent genitalia. Studia Dipterologica 1998 , 5(2):2 | 7-248.

37. Eberhard WG: Sexual morphology of male Sepsis cynipsea (Diptera: Sepsidae): lack of support for lock-and-key and sexually antagonistic morphological coevolution hypotheses. Canadian Entomologist 2005, I37(5):55 I-565.

38. Hosken DJ, Martin OY, Born J, Huber F: Sexual conflict in Sepsis cynipsea: female reluctance, fertility and mate choice. Journal of Evolutionary Biology 2003, I 6(3):485-490.

39. Kraushaar URS, Blanckenhorn WU: Population variation in sexual selection and its effect on size allometry in two dung fly species with contrasting sexual size dimorphism. Evolution 2002, 56(2):307-32I.

40. Martin OY, Leugger RR, Zeltner N, Hosken DJ: Male age, mating probability and mating costs in the fly Sepsis cynipsea. Evolutionary Ecology Research 2003, 5( I): I 19-129.

41. Muhlhauser C, Blanckenhorn WU: The quantitative genetics of sexual selection in the dung fly Sepsis cynipsea. Behaviour 2004, I 4 I(3):327-34I.

42. Parker GA: Reproductive behaviour of Sepsis cynipsea (L.) (Diptera: Sepsidae) I. A preliminary analysis of the reproductive strategy and its associated behaviour patterns. Behaviour 1972, 4 I: I 72-206.

43. Teuschl Y, Blanckenhorn WU: The reluctant fly: what makes Sepsis cynipsea females willing to copulate? Animal Behaviour 2007, 73(I):85-97.

44. Eberhard WG: The functional morphology of species-specific clasping structures on the front legs of male Archisepsis and Palaeosepsis flies (Diptera, Sepsidae). Zoological Journal of the Linnean Society 200I, I 33(3):335-368.

45. Ingram KK, Laamanen T, Puniamoorthy N, Meier R: Lack of morphlogical coevolution between male forelegs and female wings in Themira (Sepsidae: Dipera: Insecta). Biological Journal of the Linnean Society 2008, 93:227-238.

46. Blanckenhorn WU, Muhlhauser C, Morf C, Reusch T, Reuter M: Female choice, female reluctance to mate and sexual selection on body size in the dung fly Sepsis cynipsea. Ethology 2000 , I 06(7):577-593.

47. Ward PI, Hemmi ], Roosli T: Sexual Conflict in the Dung Fly Sepsis-Cynipsea. Functional Ecology 1992, 6(6):649-653.

48. Wilkinson GS, Taper M: Evolution of genetic variation for condition-dependent traits in stalk-eyed flies. Proceedings of the Royal Society (London) B 1999, 266:1685-1690.

49. Eberhard WG: Courtship and multi-stage transfer of material to the female's wings during copulation in Microsepsis armillata (Diptera: Sepsidae). Journal of the Kansas Entomological Society 200I, 74(2):70-78.

50. Muehlhaeuser C, Blanckenhorn WU: The costs of avoiding matings in the dung fly Sepsis cynipsea. Behavioral Ecology 2002, I3(3):359-365

5l. Eberhard WG: The relation between aggressive and sexual behavior and allometry in Palaeosepsis dentatiformis flies (Diptera: Sepsidae). Journal of the Kansas Entomological Society 2002, 75(4):317-332.

52. Eberhard WG. The function of female resistance behavior: Intromission by male coercion vs. female cooperation in sepsid flies (Diptera : Sepsidae). Revista De Biologia Tropical 2002, 50(2):485-505

53. Maddison WP: A Method for Testing the Correlated Evolution of 2 Binary Characters - Are Gains or Losses Concentrated on Certain Branches of a Phylogenetic Tree. Evolution 1990, 44(3):539-557

54. Martin OY, Hosken DJ: Copulation reduces male but not female longevity in Saltella sphondylli (Diptera : Sepsidae). Journal of Evolutionary Biology 2004, I 7(2):357-362.

55. Su KFY, Kutty S, Meier R: Morphology versus Molecules: The phylogenetic relationships of Sepsidae (Diptera: Cyclorrhapha) based on morphology and DNA sequence data from ten genes. Cladistics in press.

56. Ronquist F, Huelsenbeck JP: MrBayes 3: Bayesian phylogenetic inference under mixed models. Bioinformatics 2003 I 9(I 2): I572-1574

57. Nylander JAA: MrModeltest. 2.0th edition. Uppsala, Evolutionary Biology Centre, Uppsala University; 2004.

58. Maddison DR, Maddison WP: MacClade 4: Interactive Analysis of Phylogeny and Character Evolution. 4.0I th edition. Sunderland, MA, Sinauer Associates; 2000.

59. Themira + Nemopoda [http://www.youtube.com/ watch? $\mathrm{v}=\mathrm{Z}$ leWft|rU2M]

60. Australosepsis + Sepsis [http://www.youtube.com/watch?v=C KQD90yLo]

61. Five genera of sepsid flies with 'typical' mount [http:// www.youtube.com/watch?v=lQkm8exIFDY]

62. Orygma luctuosum [http://www.youtube.com watch?v=R9Pwe98LNMc]

63. Perochaeta watch?v=T33Yr9cd5zg]

[http://www.youtube.com/

64. Ang Y, Puniamoorthy N, Meier R: Secondarily reduced foreleg armature in Perochaeta dikowi sp. n. (Diptera: Cyclorrhapha: Sepsidae) due to a novel mounting technique. Systematic Entomology 2008.

65. Sepsis secunda watch?v=ZOs9Yg6bPvY

[http://www.youtube.com/

66. Crean CS, Dunn DW, Day TH, Gilburn AS: Female mate choice for large males in several species of seaweed flies (Diptera: Coelopidae). Animal Behaviour 2000, 59(1):121-126.

67. Weall CV, Gilburn AS: Factors influencing the choice of female mate rejection strategies in the seaweed fly Coelopa nebularum (Diptera: Coelopidae). Journal of Insect Behavior 2000, I3(4):539-552

68. Day TH, Gilburn AS: Sexual selection in seaweed flies. Advances in the Study of Behaviour 1997, 26: 1-57.

69. Bonduriansky R, Brooks RJ: Copulation and oviposition behaviour of Protopiophila litigata (Diptera : Piophilidae). Canadian Entomologist 1998, I30(4):399-405

70. Otronen M: Mating behavior and sperm competition in the fly, Dryomyza anilis. Behavioral Ecology and Sociobiology 1990 , 26:349-356. 
71. Baer CF, Lynch M: Correlated evolution of life-history with size at maturity in Daphnia pulicaria: patterns within and between populations. Genetical Research 2003, 81:123-132.

72. Day TH, Foster SP, Engelhard G: Mating Behavior in Seaweed Flies (Coelopa-frigida). Journal of Insect Behavior 1989, 3(I): 105-120.

73. McAlpine DK: Review of the Australian kelp flies (Diptera: Coelopidae). Systematic Entomology 1991, 16(1):29-84.

74. Dodson G: Resource defence mating system in antlered flies, Phytalmia spp. (Diptera: Tephritidae). Annals of the Entomological Society of America 1997, 90:496-504.

75. Meier R, Kwong S, Vaidya G, Ng PKL: DNA Barcoding and Taxonomy in Diptera: a Tale of High Intraspecific Variability and Low Identification Success. Systematic Biology 2006, 55:715-728.

76. Eberhard WG: Physical restraint or stimulation? The function(s) of the modified front legs of male Archisepsis diversiformis (Diptera, Sepsidae). Journal of Insect Behavior 2002, I 5(6):83|-850.

77. Lung O, Tram U, Finnerty CM, Eipper-Mains MA, Kalbs JM, Wolfner MF: The Drosophila melanogaster seminal fluid protein Acp62F is a protease inhibitor that is toxic upon ectopic expression. Genetics 2002, 160:211-224.

78. Chapman T: Seminal fluid-mediated fitness traits in Drosophila. Heredity 200I, 87(Pt 5):5II-52I.

79. Friberg U: Genetic variation in male and female reproductive characters associated with sexual conflict in Drosophila melanogaster. Behavior Genetics 2005, 35(4):455-462.

80. Wigby S, Chapman T: Female resistance to male harm evolves in response to manipulation of sexual conflict. Evolution 2004, 58(5): $1028-1037$.

8I. Otronen M: Repeated Copulations as a Strategy to Maximize Fertilization in the Fly, Dryomyza-Anilis (Dryomyzidae). Behavioral Ecology 1994, 5(I):5 I-56.

82. Martin OY, Hosken DJ: Reproductive consequences of population divergence through sexual conflict. Current Biology 2004, 14(10):906-910.

83. Felsenstein J: Phylogenies and the comparative method. Am Nat 1985, 125(I): I-15.
Publish with Biomed Central and every scientist can read your work free of charge

"BioMed Central will be the most significant development for disseminating the results of biomedical research in our lifetime. "

Sir Paul Nurse, Cancer Research UK

Your research papers will be:

- available free of charge to the entire biomedical community

- peer reviewed and published immediately upon acceptance

- cited in PubMed and archived on PubMed Central

- yours - you keep the copyright
BioMedcentral 